\title{
Investigation of the Antioxidant and Antibacterial Activity of Novel Quercetin Derivatives
}

\author{
Shaker A. N. Aljadaan 1(D), Rita S Elias 2,* (D), Reham Adnan Al-Anssari 3,* (D) \\ Department of Pharmaceutical Chemistry, College of Pharmacy, University of Basrah, Basrah, Iraq \\ Department of Pharmaceutical Chemistry, College of Pharmacy, University of Basrah, Basrah, Iraq \\ Department of pharmacognosy and medicinal plants, College of Pharmacy, University of Basrah, Basrah, Iraq \\ * Correspondence: rita_phar@yahoo.com;
}

Received: 28.04.2020; Revised: 1.06.2020; Accepted: 3.06.2020; Published: 8.06.2020

\begin{abstract}
Our previous work involved the preparation and characterization of six quercetin derivatives, three of which were novel Schiff bases, while the fourth was a novel ionic salt of iodine. This study involved the investigation of the in vitro antioxidant activity against DPPH free radical as well as the in vitro antibacterial activity against Bacillus cereus, Salmonella spp., Escherichia coli and Staphylococcus aureus of quercetin and its 1-6 derivatives. The results revealed that all the studied quercetin derivatives had shown less antioxidant and antibacterial activity than quercetin itself, except that of compounds 3 and 4, which displayed an improvement in the antibacterial activity against Escherichia coli as compared to that of quercetin.
\end{abstract}

Keywords: Quercetin; antioxidant; DPPH; antibacterial.

(C) 2020 by the authors. This article is an open-access article distributed under the terms and conditions of the Creative Commons Attribution (CC BY) license (https://creativecommons.org/licenses/by/4.0/).

\section{Introduction}

Quercetin (Figure 1) is a pentahydroxyflavone that is considered to be one of the most important flavonoids because of its widespread within the food, broad biological actions and versatile physiological effects such as antioxidant, anticancer, antimicrobial, antiinflammatory, anti-diabetic, prevention of cardiovascular disease, neuroprotective, and antiobesity activities [1-18].<smiles></smiles>

Figure 1. Chemical structure of quercetin.

Schiff bases, on the other hand, involve compounds that bear an imine or azomethine group within their chemical structure [19, 20] (Figure 2) such group has been linked to the biological activity of many compounds, such as antimalarial, antibacterial, antifungal, and antiviral activities [20-22].<smiles>[R9]N=C([R])[R]</smiles>

Figure 2. Chemical structure of Schiff base. 
The antioxidant activity has been chosen to be investigated due to the tight relationship between oxidative stress and several malignant diseases such as cancer and cardiovascular pathologies, which point to the important role of the antioxidant compounds in maintaining the integrity of our living systems. Our study also involves an in vitro study of the potential antibacterial activity of quercetin and its (1-6) analog due to the spreading out of bacterial resistance to most known antibiotics and hence increasing the requirement to develop new antibacterial agents.

\section{Materials and Methods}

\subsection{Materials.}

DPPH, DMSO, ethanol 99\% were purchased from Sigma-Aldrich (Germany), while Molar Hinton agar, Mannitol salt agar were obtained from Himedia (India), and EMB agar from oxoid (United Kingdom).

\subsection{Chemical synthesis.}

Six quercetin derivatives (compound 1-6) were synthesized and described previously [23] (Figure 3).

\subsection{In vitro Antioxidant activity of quercetin and its 1-6 derivatives.}

Studying the in vitro antioxidant activity of the quercetin and its 1-6 derivatives was performed by monitoring their effect on the absorbance of $0.1 \mathrm{mM}$ of the stable free radical 2,2-diphenyl-1-picrylhydrazyl (DPPH) at $517 \mathrm{mM}$ following the procedure described by $\mathrm{U}$. Krings and R.G. Berger [24] and Zheng Chen and coworkers [25]. 1mM ethanolic stock solutions of quercetin and the studied derivatives were prepared, from which different concentrations $(0.1,0.05,0.02,0.01,0.001 \mathrm{mM})$ were made by mixing appropriate volumes with ethanol and $0.1 \mathrm{~mL}$ of $1 \mathrm{mM}$ ethanolic DPPH solution followed by incubation in the darkness for about 30 minutes. The absorbance of each concentration was then measured at $517 \mathrm{~nm}$ using a quartz cell. Each concentration was established in triplicate and the percentages of inhibitory activity to DPPH of each concentration after 30 minutes was calculated from the equation (Eq.1) and were plot against tested concentrations in order to determine the amount required to reduce the initial concentration of DPPH by $50 \%$ (IC 50 ) for each compound.

$$
\% \mathrm{DPPH} \text { remaining }=(\mathrm{A} \text { control }-\mathrm{A} \text { sample }) / \mathrm{A} \text { control } * 100 \% \quad(\text { Eq. } 1)
$$

Where \% DPPH remaining represents the percentage of the remaining DPPH after 30 minutes of sample addition; A sample is the absorbance of the DPPH radical in the presence of sample; while A control refers to the absorbance of the $0.1 \mathrm{mM}$ DPPH radical alone.

\subsection{In vitro Antibacterial activity of quercetin and its 1-6 derivatives.}

Agar well diffusion method was used to explore the antibacterial activity of quercetin and (1-6) derivatives as described by Mounyer Balouiri and coworkers [26]. The antibacterial activity was studied against 4 types of bacteria namely Bacillus cereus, Escherchia coli, Salmonella spp and Staphylococcus aureus Three concentrations of each compound were prepared $(0.25,0.5$ and $1 \mathrm{mg} / \mathrm{mL})$ by dissolving quercetin and compounds $1,2,5$ and 6 in DMSO while compounds 3 and 4 were decomposed in this solvent so were dissolved in absolute ethanol. A day before, each bacterial strain was activated by spreading them on their 
selective media and keeping them for 24 hours within incubator (Binder, FD23, USA), then a diluted suspension of each bacteria was prepared using $0.9 \% \mathrm{NaCl}$. A suitable concentration was determined by comparing bacterial suspension turbidity against $0.5 \mathrm{McFarland}$ standard. Mueller - Hinton agar plate surface was inoculated by the spreading of the bacterial inoculum over the whole agar surface using swap. Then, a hole with a diameter of $5 \mathrm{~mm}$ was made with a sterile yellow tip, and a $100 \mu \mathrm{L}$ of each of the desired concentration of the studied compounds were injected into the well. A control well within the same agar plate was injected with DMSO or ethanol. The agar plates were then incubated for $18-24$ hours at $37^{\circ} \mathrm{C}$ in the incubator, after which the diameter of the inhibition zone was measured. The introduced compounds were diffused in the agar medium and act to inhibit the growth of the tested bacterial strain. Selected antibiotic discs were introduced into other agar plates inoculated with similar bacterial strains to test bacterial sensitivity to them.

\subsection{Statical analysis.}

Data were analyzed with Microsoft excel 2010, and results were expressed as mean \pm standard deviation. All measurements were evaluated using a student t-test designed to examine the difference in activity between the standard quercetin and its 1-6 derivatives. A $p$-value $<0.05$ was used to assess significance.

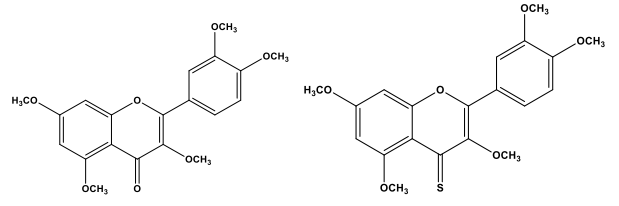

(1) (2)

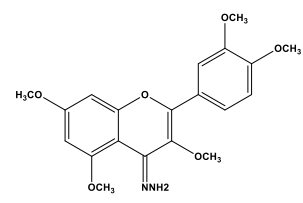

(3)

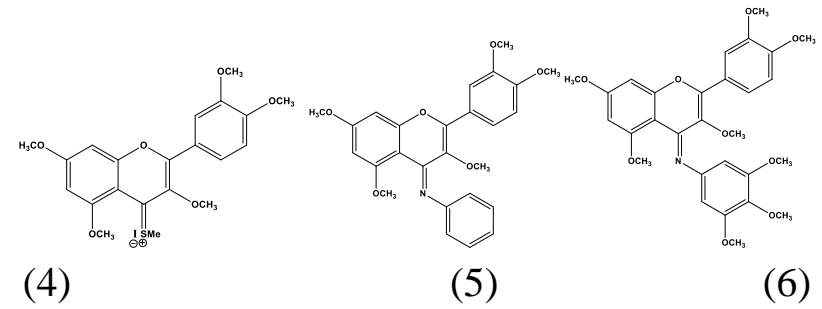

Figure 3. Chemical structure of compounds 1-6.

\section{Results and Discussion}

\subsection{In vitro Antioxidant activity of quercetin and its 1-6 derivatives.}

In vitro antioxidant activity of quercetin and its 1-6 derivatives study results are shown in Table 1 and figures 4 and 5. The radical scavenging activity of the prepared quercetin derivatives was estimated by monitoring the reduction of light absorbance at $517 \mathrm{~nm}$ of DPPH radical upon its reaction with different concentrations of quercetin derivatives in ethanol, then their percentages of antiradical activity were calculated as shown in equation (Eq.2) and plotted against the different studied concentrations in order to get the equation necessary to verify the half-maximal inhibitory concentration ( $\mathrm{IC}_{50}$ ) for each studied compound against $\mathrm{DPPH}$ as shown in Table 1 and Figures 4 and 5.

$$
\% \text { Of antioxidant activity }=(\mathrm{A}-\mathrm{A} 30 \mathrm{~min} .) / \mathrm{A} * 100 \%
$$

Where A account for the absorption of DPPH solution, A30 absorption of DPPH after 30 minutes of antioxidant addition. 
Quercetin molecule is characterized by high antioxidant activity that is superior to vitamin $C$ when both were used at low concentrations [27], this activity referred to the strong electron-donating effect of the hydroxyl groups to the conjugated $\pi$-system and the relative planer structure of the quercetin molecule which aid in charge distribution over the whole molecule. Therefore it is expected from the studied compounds (1-6) to show lower antioxidant activity than the parent compound since all the hydroxyl groups within the quercetin molecule were methylated and as were confirmed by previous studies $[6,28]$. However, the $\mathrm{IC}_{50}$ values of the studied compounds 3 and 4 revealed the highest antioxidant activity, followed by compound $6,2,5$, and 1 subsequently. In fact, at $0.1 \mathrm{mM}$ concentration compound, 4 showed comparable radical scavenging activity to quercetin, but unlike quercetin [27] this activity rapidly dropped at a lower concentration, whereas a slower decline in the antioxidant potential was exposed by compound 3 at similar concentrations, giving it better IC 50 values than compound 4.

The antioxidant activity of compound 4 might be referred to the presence of iodine in the ionic form within compound 4 chemical structure, iodine is known for its antiradical effects, iodide ion $\left(\mathrm{I}^{-}\right)$react with free radicals $(\mathrm{R})$ to give iodine radical $\left(\mathrm{I}^{\bullet}\right)$ which immediately converted into molecular iodine, the later is considered to be a good oxidant and potential prooxidant agent as shown in equations (Eq.3) and (Eq.4)[29].

$$
\begin{aligned}
& \mathrm{R}+\mathrm{I}^{-} \rightarrow \mathrm{R}:+\mathrm{I} \\
& 2 \mathrm{I} \rightarrow \mathrm{I}_{2}
\end{aligned}
$$

In addition to the direct interaction with free radicals of iodine, some studies have correlated it's in vivo antioxidant activity with its ability to iodinate certain amino acids and fatty acids and thus reducing their ability to oxidize themselves [29, 30]. On the other hand, the scavenging activity of compound 3 can be attributed to the presence of the $\mathrm{NH}_{2}$ group in the hydrazone moiety, which can donate a hydrogen atom to the DPPH free radical, and the resulting free radical would be possibly stabilized by delocalization into the flavone backbone. On the other hand, the antioxidant activity of compounds 5, 2, 6 and 1 are close to each other and much lower than the previously mentioned compounds, possibly because there is no free available hydrogen atom to be donated directly to stabilize the DPPH radical.

\subsection{In vitro Antibacterial activity of quercetin and its 1-6 derivatives.}

The antibacterial activities of quercetin and its 1-6 derivatives were assayed in vitro against four types of bacteria, two of these were gram-positive (Bacillus cereus and Staphylococcus aureus), and two were gram-negative bacteria (Escherichia coli and Salmonella spp.). At tested concentrations, a variable degree of antibacterial activity have been detected among the studied compounds against Staphylococcus aureus, while Escherichia coli growth inhibition was detected only for compounds 3 and 4, and neither quercetin nor any of the studied derivatives have shown any activity against Bacillus cereus or Salmonella spp. Additionally, compounds 1, 2, 5, and 6 demonstrate no antibacterial activity at studied concentrations, possibly due to an increase in the hydrophobicity of the molecule $[28,31]$. Antibacterial activity results of quercetin and compounds 1-6 were displayed in Table 2 and figure 6-8. Two standard antibiotic disks were used for the comparison and found to exert their antibacterial action at relatively lower concentrations than our studied compounds. 
Table 1. The percentage of activity of different concentrations of quercetin and compounds 1-6 against DPPH.

\begin{tabular}{|c|c|c|c|c|c|c|c|}
\hline \multirow{2}{*}{$\begin{array}{c}\text { Concentration } \\
(\mathbf{m M})\end{array}$} & \multicolumn{7}{|c|}{ Compounds Activity (\%) } \\
\hline & Quercetin & $\mathbf{1}^{\mathrm{a}}$ & $2^{\mathrm{a}}$ & 3 & 4 & $5^{a}$ & $\mathbf{6}^{\mathbf{a}}$ \\
\hline 0.1 & $93.3 \pm 0.37$ & $9.6 \pm 5.1$ & $13.3 \pm 4.5$ & $82.4 \pm 0.5$ & $92.9+1.0$ & $11.5 \pm 1.2$ & $23.0 \pm 1.6$ \\
\hline 0.05 & $92.1 \pm 0.25$ & $6.3 \pm 0.9$ & $13.2 \pm 3.2$ & $68.5 \pm 4.0$ & $55.3 \pm 6.2$ & $4.6 \pm 0.6$ & $14.5 \pm 3.3$ \\
\hline 0.02 & $84.2 \pm 0.21$ & $3.5 \pm 2.3$ & $4.5 \pm 0.5$ & $37.5 \pm 6.5$ & $19.5 \pm 2.6$ & $2.6 \pm 0.4$ & $8.7 \pm 1.7$ \\
\hline 0.01 & $61.9 \pm 0.78$ & $3.0 \pm 0.4$ & $2.2 \pm 1.4$ & $19.3 \pm 5.3$ & $5.3 \pm 1.6$ & $2.3 \pm 1.4$ & $1.3 \pm 1.0$ \\
\hline 0.001 & $20.3 \pm 0.46$ & $2.1 \pm 2.4$ & $0.93 \pm 1.1$ & $2.7 \pm 2.9$ & $0.71 \pm 0.7$ & $1.4 \pm 1.6$ & $3.7 \pm 0.8$ \\
\hline $\mathrm{IC}_{50}$ & 0.004 & 0.62 & 0.36 & 0.04 & 0.05 & 0.49 & 0.22 \\
\hline
\end{tabular}
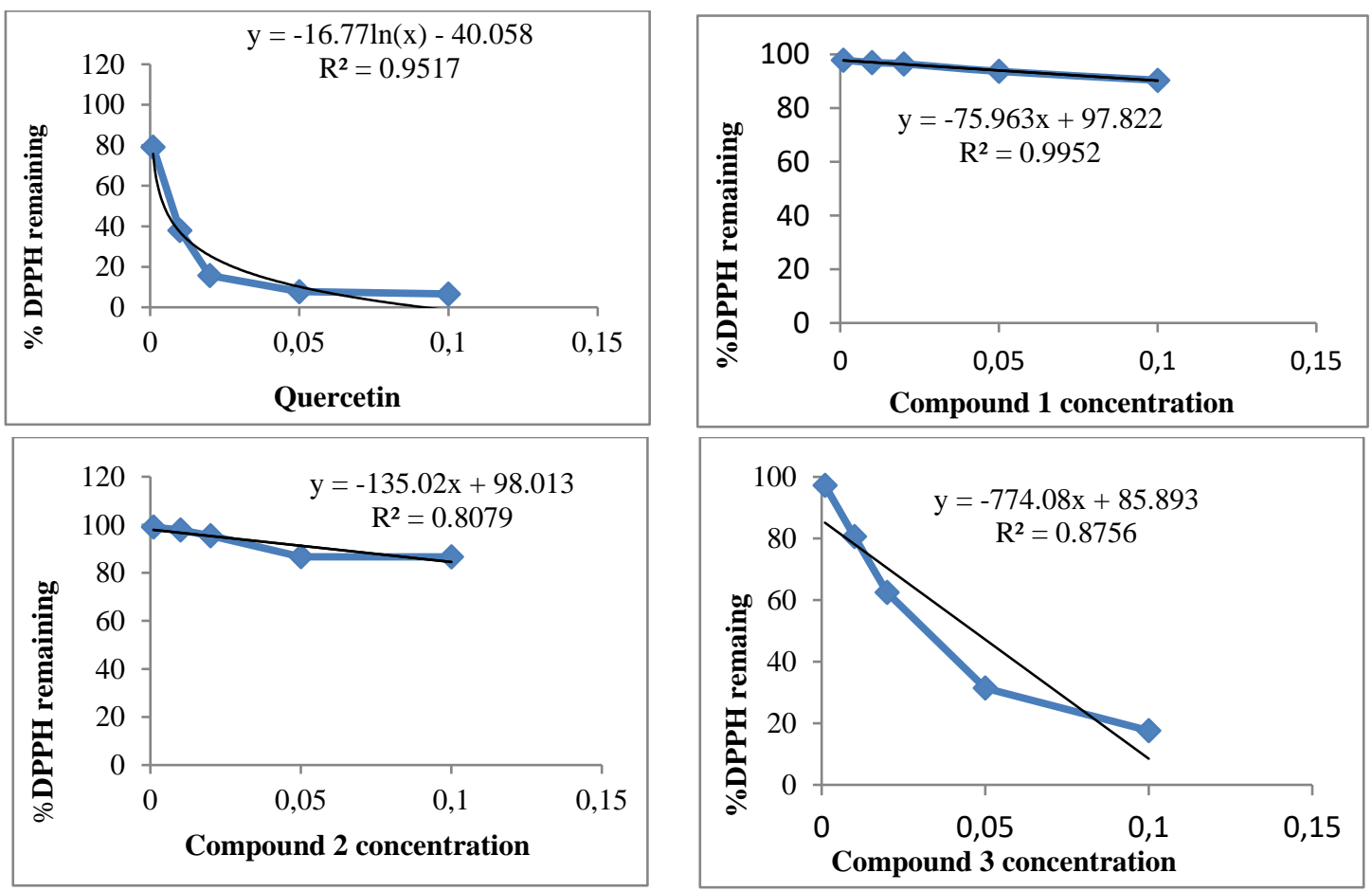

Figure 4. The effect of different concentrations of quercetin and compounds 1-3 on the percentage of DPPH remaining.
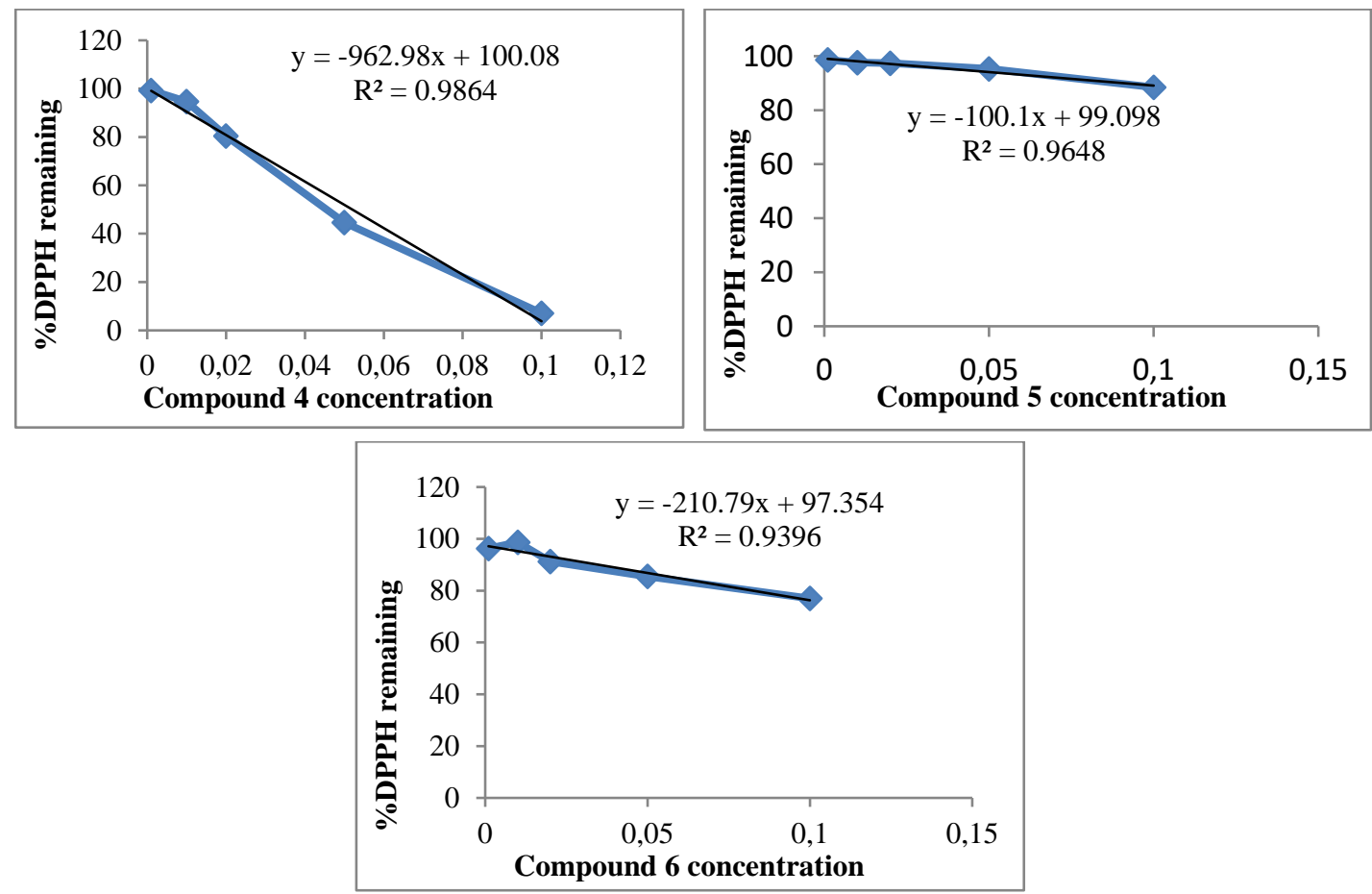

Figure 5. The effect of different concentrations compounds 4-6 on the percentage of DPPH remaining. 
Table 2. Antibacterial activity of quercetin and compounds 1-6 against bacterial strains.

\begin{tabular}{|c|c|c|c|c|c|}
\hline \multirow{2}{*}{ Compound } & \multirow{2}{*}{$\begin{array}{c}\text { Conc. } \\
\text { mg/mL }\end{array}$} & \multicolumn{4}{|c|}{ Mean Inhibition zone diameter (mm)a } \\
\hline & & Staph.aureus & B. cereus & E.coli & Salmonella spp. \\
\hline \multirow[t]{3}{*}{ Quercetin } & 0.25 & & & & \\
\hline & 0.5 & 7 & & & \\
\hline & 1 & 12 & & & \\
\hline \multirow[t]{3}{*}{1} & 0.25 & & & & \\
\hline & 0.5 & & & & \\
\hline & 1 & & & & \\
\hline \multirow[t]{3}{*}{2} & 0.25 & & & & \\
\hline & 0.5 & & & & \\
\hline & 1 & & & & \\
\hline \multirow[t]{3}{*}{3} & 0.25 & 6 & & 6 & \\
\hline & 0.5 & 7 & & 6 & \\
\hline & 1 & 12 & & 7 & \\
\hline \multirow[t]{3}{*}{4} & 0.25 & & & 6 & \\
\hline & 0.5 & 6 & & 7 & \\
\hline & 1 & 8 & & 11 & \\
\hline \multirow[t]{3}{*}{5} & 0.25 & & & & \\
\hline & 0.5 & & & & \\
\hline & 1 & & & & \\
\hline \multirow[t]{3}{*}{6} & 0.25 & & & & \\
\hline & 0.5 & & & & \\
\hline & 1 & & & & \\
\hline Ciprofloxacin & 0.01 & 31 & 28 & 32 & 20 \\
\hline Gentamicin & 0.01 & 19 & 20 & 15 & 15 \\
\hline
\end{tabular}

${ }^{\mathrm{a}}$ Hole diameter $(=5 \mathrm{~mm})$ was not subtracted.

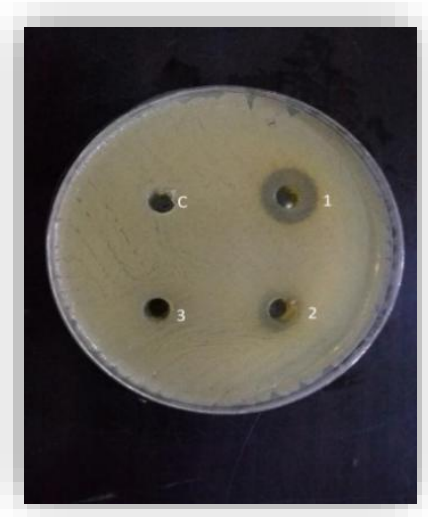

Figure 6. Quercetin activity against Staphylococcus aureus and where 1, 2, 3 and C represent 1, 0.5, 0.25 $\mathrm{mg} / \mathrm{mL}$ and control solvent respectively.

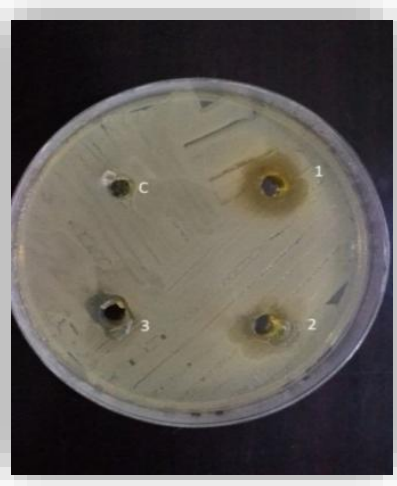

(A)

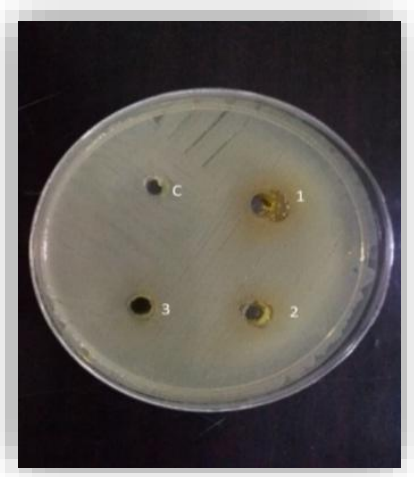

(B)

Figure 7. Compound 3 activity against (A) Staphylococcus aureus and (B) Escherchia coli where 1, 2, 3 and C represent $1,0.5,0.25 \mathrm{mg} / \mathrm{ml}$ and control solvent. 


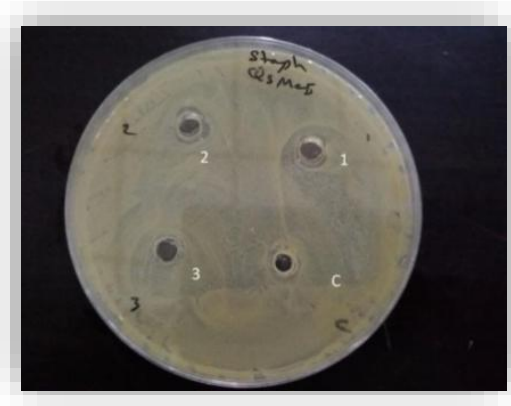

(A)

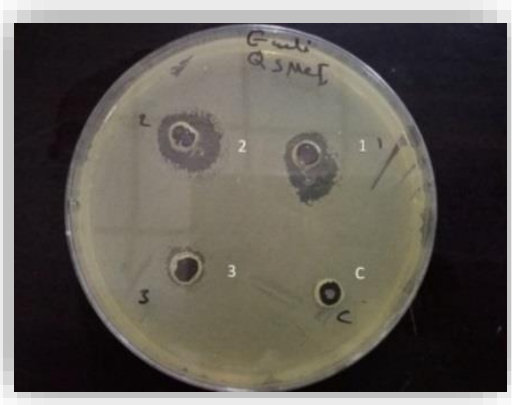

(B)

Figure 8. Compound 4 activity against (A) Staphylococcus aureus and (B) Escherchia coli where 1, 2, 3 and C represent $1,0.5,0.25 \mathrm{mg} / \mathrm{ml}$ and control solvent.

\section{Conclusions}

On the basis of our results we conclude that at tested concentrations quercetin show superior antioxidant and antibacterial activity compared to its 1-6 derivatives, but, however, compound 3 and 4 in vitro antibacterial activity results reveal significant improvement in the gram-negative antibacterial activity against Escherichia coli as compared to that of quercetin.

\section{Funding}

This research received no external funding.

\section{Acknowledgments}

This research has no acknowledgment.

\section{Conflicts of Interest}

The authors declare no conflict of interest.

\section{References}

1. Pietta, P.-G. Flavonoids as Antioxidants. Journal of Natural Products 2000, 63, 1035-1042, https://doi.org/10.1021/np9904509.

2. Ramos, F.A.; Takaishi, Y.; Shirotori, M.; Kawaguchi, Y.; Tsuchiya, K.; Shibata, H.; Higuti, T.; Tadokoro, T.; Takeuchi, M. Antibacterial and Antioxidant Activities of Quercetin Oxidation Products from Yellow Onion (Allium cepa) Skin. Journal of Agricultural and Food Chemistry 2006, 54, 3551-3357, https://doi.org/10.1021/jf060251c.

3. Wang, W.; Sun, C.; Mao, L.; Ma, P.; Liu, F.; Yang, J.; Gao, Y. The biological activities, chemical stability, metabolism and delivery systems of quercetin: A review. Trends in Food Science \& Technology 2016, 56, 21-38, https://doi.org/10.1016/j.tifs.2016.07.004.

4. Amic, D.; Davidovic-Amic, D.; Beslo, D.; Rastija, V.; Lucic, B.; Trinajstić, N. SAR and QSAR of the antioxidant activity of flavonoids. Current Medicinal Chemistry 2007, 14, 827-845, https://doi.org/10.2174/092986707780090954.

5. D'Andrea, G. Quercetin: A flavonol with multifaceted therapeutic applications. Fitoterapia 2015, 106, 256271, https://doi.org/10.1016/j.fitote.2015.09.018.

6. Moalin, M.; Strijdonck, G.P.; Beckers, M.; Hagemen, G.; Borm, P.; Bast, A.; Haenen, G.R. A planar conformation and the hydroxyl groups in the $\mathrm{B}$ and $\mathrm{C}$ rings play a pivotal role in the antioxidant capacity of quercetin and quercetin derivatives. Molecules 2011, 16, 9636-9650, https://doi.org/10.3390/molecules16119636.

7. Procházková, D.; Boušová, I.; Wilhelmová, N. Antioxidant and prooxidant properties of flavonoids. Fitoterapia 2011, 82, 513-523, https://doi.org/10.1016/j.fitote.2011.01.018. 
8. Massi, A.; Bortolini, O.; Ragno, D.; Bernardi, T.; Sacchetti, G.; Tacchini, M.; De Risi, C. Research Progress in the Modification of Quercetin Leading to Anticancer Agents. Molecules 2017, 22, 1270, https://doi.org/10.3390/molecules22081270.

9. Dajas, F. Life or death: neuroprotective and anticancer effects of quercetin. Journal of Ethnopharmacology 2012, 143, 383-396, https://doi.org/10.1016/j.jep.2012.07.005.

10. Al-Jadaan, S.; Al-Diwan, M. Synthesis, Characterization and Antioxidant activity of Novel Quercetin derivative. Life Science Archives 2018, 4, 1260-1272, https://doi.org/10.22192/lsa.2018.4.1.3.

11. Xu, D.; Hu, M.-J.; Wang, Y.-Q.; Cui, Y.-L. Antioxidant Activities of Quercetin and Its Complexes for Medicinal Application. Molecules 2019, 24, 1123. https://doi.org/10.3390/molecules24061123.

12. Bule, M.; Abdurahman, A.; Nikfar, S.; Abdollahi, M.; Amini, M. Antidiabetic effect of quercetin: A systematic review and meta-analysis of animal studies. Food and Chemical Toxicology 2019, 125, 494-502, https://doi.org/10.1016/j.fct.2019.01.037.

13. Khan, H.; Ullah, H.; Aschner, M.; Cheang, W.S.; Akkol, E.K. Neuroprotective Effects of Quercetin in Alzheimer's Disease. Biomolecules 2019, 10, 1-20, https://doi.org/10.3390/biom10010059.

14. Xian-Jun, W.; Xin-Bin, Z.; Chen, C.; Wei, M. Systematic Investigation of Quercetin for Treating Cardiovascular Disease Based on Network Pharmacology. Combinatorial Chemistry \& High Throughput Screening 2019, 22, 411-420, https://doi.org/10.2174/1386207322666190717124507.

15. Kundur, S.; Prayag, A.; Selvakumar, P.; Nguyen, H.; McKee, L.; Cruz, C.; Srinivasan, A.; Shoyele, S.; Lakshmikuttyamma, A. Synergistic anticancer action of quercetin and curcumin against triple-negative breast cancer cell lines. Journal of Cellular Physiology 2019, 234, 11103-11118, https://doi.org/10.1002/jcp.27761.

16. Rauf, A.; Imran, M.; Khan, I.A.; Ur-Rehman, M.; Gilani, S.A.; Mehmood, Z.; Mubarak, M.S. Anticancer potential of quercetin: A comprehensive review. Phytother Res. 2018, 32, 2109-2130, https://doi.org/10.1002/ptr.6155.

17. Carrasco-Pozo, C.; Cires, M.J.; Gotteland, M. Quercetin and Epigallocatechin Gallate in the Prevention and Treatment of Obesity: From Molecular to Clinical Studies. Journal of Medicinal Food 2019, 22, 753-770, https://doi.org/10.1089/jmf.2018.0193.

18. Mathiyalagan, S.; Mandal, B.K. Preparation of metal doped quercetin nanoparticles, characterization and their stability study. Letters in Applied NanoBioScience 2019, 8, 704-710, https://doi.org/10.33263/LIANBS84.704710.

19. Berhanu, A.L.; Gaurav;Mohiuddin, I.; Malik, A.K.; Aulakh, J.S.; Kumar, V.; Kim, K.-H. A review of the applications of Schiff bases as optical chemical sensors. Trends in Analytical Chemistry (TrAC) 2019, 116, 74-91, https://doi.org/10.1016/j.trac.2019.04.025.

20. Ayoubi, M.; Foroughifar, N.; Khajeh-Amiri, A.; Foroughifar, N. Synthesis, characterization and study the biological evaluation of some Schiff base derivatives in the presence of lemon juice catalyst. Biointerface Research in Applied Chemistry 2019, 9, 4187-4192, https://doi.org/10.33263/BRIAC94.187192.

21. da Silva, C.M.; da Silva, D.L.; Modolo, L.V.; Alves, R.B.; de Resende, M.A.; Martins, C.V.B.; de Fátima, $\hat{A}$. Schiff bases: A short review of their antimicrobial activities. Journal of Advanced Research 2011, 2, 18, https://doi.org/10.1016/j.jare.2010.05.004.

22. Rao, D.P. A review on versatile applications of novel Schiff bases and their metal complexes. Letters in Applied NanoBioScience 2019, 8, 675-681, https://doi.org/10.33263/LIANBS84.675681.

23. Al-Anssari, R.A.; Elias, R.S.; Aljadaan, S.A.N. Synthesis, Ant Proliferative Activity and Docking Study of New Quercetin Derivatives against MDA-MB231 Breast Cancer Cell Lines. American Journal of Applied Sciences 2019, 16, 143-161, https://doi.org/10.3844/ajassp.2019.143.161.

24. Krings, U.; Berger, R.G. Antioxidant activity of some roasted foods. Food Chemistry 2001, 72, 223-229, https://doi.org/10.1016/S0308-8146(00)00226-0.

25. Chen, Z.; Bertin, R.; Froldi, G. EC50 estimation of antioxidant activity in DPPH assay using several statistical programs. Food chemistry 2013, 138, 414-420,https://doi.org/10.1016/j.foodchem.2012.11.001

26. Balouiri, M.; Sadiki, M.; Ibnsouda, S.K. Methods for in vitro evaluating antimicrobial activity: A review. Journal of Pharmaceutical Analysis 2016, 6, 71-79, https://doi.org/10.1016/j.jpha.2015.11.005.

27. Majewska, M.; Skrzycki, M.; Podsiad, M.; Czeczot, H. Evaluation of antioxidant potential of flavonoids: an in vitro study. Acta Poloniae Pharmaceutica 2011, 68, 611-615, https://pubmed.ncbi.nlm.nih.gov/21796946/.

28. Kim, M.; Park, Y.; Cho, S.; Burapan, S.; Han, J. Synthesis of alkyl quercetin derivatives. Journal of the Korean Society for Applied Biological Chemistry 2015, 58, 343-348, https://doi.org/10.1007/s13765-0150050-x.

29. Winkler, R. Iodine-A Potential Antioxidant and the Role of Iodine/Iodide in Health and Disease. Natural Science 2015, 7, 548-557, https://doi.org/10.4236/ns.2015.712055.

30. Smyth, P.P. Role of iodine in antioxidant defence in thyroid and breast disease. Biofactors 2003, 19, 12130, https://doi.org/10.1002/biof.5520190304.

31. Woznicka, E.; Kuzniar, A.; Nowak, D.; Nykiel, E.; Kopacz, M.; Gruszecka, J.; Golec, K. Comparative study on the antibacterial activity of some flavonoids and their sulfonic derivatives. Acta Poloniae Pharmaceutica 2013, 70, 567-571, https://www.ncbi.nlm.nih.gov/pubmed/23757948. 